\title{
Entegre zararlı yönetimi ve gelişmekte olan ülkelerdeki durumu
}

\section{Integrated pest management and its status in developing countries}

\author{
Emre inAK $^{1}$ iD, Esengül ÖZdEMiR ${ }^{1}$ iD, Y. Nazım ALPKENT $^{2}$ iD Arda inAK $^{3}$ iD Cem ÖZKAN $^{1}$ iD \\ ${ }^{1}$ Ankara Üniversitesi Ziraat Fakültesi Bitki Koruma Bölümü, Dışkapı, Ankara \\ ${ }^{2}$ Zirai Mücadele Merkez Araştırma Enstitüsü Müdürlüğü, Yenimahalle, Ankara \\ ${ }^{3}$ BASF Türk Kimya Sanayi ve Ticaret Ltd. Şti., Muratpaşa, Antalya
}

To cite this article:

İnak, E., Özdemir, E., Alpkent, Y.N., İnak, A. \& Özkan, C. (2019). Entegre zararlı yönetimi ve gelişmekte olan ülkelerdeki durumu. Harran Tarım ve Gıda Bilimleri Dergisi, 23(1): DOI:

10.29050/harranziraat.4263 91

\section{Address for Correspondence: Emre Inak, Esengül Özdemir e-mail: \\ einak@ankara.edu.tr, ozdemire@ankara.edu.tr}

\section{Received Date:} 23.05.2018

Accepted Date:

18.01.2019

(C) Copyright 2018 by Harran University Faculty of Agriculture. Available on-line at www.dergipark.gov.tr/harranziraat



\section{Öz}

Tarımsal zararlılar her yıl dünya genelinde milyarlarca dolar zarara neden olmaktadır. Bu zararlılar ile mücadelede, uzun yıllardan beri yoğun olarak pestisitler kullanılmaktadır. Ancak pestisitlerin yoğun ve bilinçsiz kullanımının çevre ve insan sağığına olan olumsuz etkilerinin farkedilmesi ile pestisit kullanımını azaltacak yeni mücadele stratejileri geliştirilmeye başlanmıştır. Entegre zararlı yönetimi (EZY), bu stratejiler arasında en çok benimseneni olmuştur. EZY stratejileri, ülkelerin gelişmişlik düzeyine göre farklılık göstermektedir. Gelişmiş ülkelerin neredeyse tamamı tarafından uygulanan bu sistem, maalesef en çok ihtiyaç duyulan gelişmekte olan ülkelerde ise istenen düzeyde benimsenmemiştir. Bu derlemenin amacı; EZY sistemlerinin yıllar içerisindeki gelişimi, ülkemizde ve diğer gelişmekte olan ülkelerde yapılan EZY çalışmaları ve bu stratejilerin yaygınlaşmasının önündeki engeller hakkında bilgiler vermektedir.

Anahtar Kelimeler: Entegre zararlı yönetimi, Sürdürülebilir tarım, Ekonomik zarar seviyesi, Pestisitler

\section{ABSTRACT}

Agricultural pests cause billions of dollars economic losses worldwide annually. Pesticides have been used intensively for many years in control of these pests. However, it has been noticed that intensive and unconscious use of pesticides has negative effects both on environment and human also human health. In order to reduce this intensive pesticide usage, novel control strategies have been begun to develop. Integrated pest management (IPM) has been the most adopted system among them. IPM strategies differ according to the development level of the countries. This system, which is applied by almost all of the developed countries commonly, but, unfortunately, it is not adopted at the desired level in developing countries where it is most needed. The purpose of this review is to provide information about the progress of the IPM systems over the years and IPM studies in our country and other developing countries and obstacles to its widespread adoption.

Key Words: Integrated pest management, Sustainable agriculture, Economic injury level, Pesticides

\section{Giriş}

Hızla artan dünya nüfusu ile birlikte; insanları sadece beslemek değil aynı zamanda güvenilir, sağlıklı gıda temin etmek ve sürdürülebilir tarım politikaları oluşturmak küresel bir misyon haline gelmiştir. FAO (2017)'ya göre, 2050 yılında dünya nüfusu 10 milyar civarına yükselecek ve tarımsal üretime olan ihtiyaç daha da artacaktır. Kaldı ki günümüzde bile yetersiz beslenen insan sayısı 2015 yılında 777 milyon iken, 2016 yılında bu sayı 815 milyona ulaşmıştır (FAO, 2017) ve ne yazık ki hızla artmaya devam etmektedir. Özellikle, 20. yüzyılın ortalarından itibaren yüksek girdili tarım 
sistemine geçilmesi ile birlikte, ilk olarak verim hızla artmış, ancak kısa zaman içerisinde bu artış hızı yavaşlayarak en sonunda doyma noktasına yaklaşmıştır. Verimi artırmaya yönelik yapılan çalışmalar büyük bir hızla devam etse de, verim artışının ivmesi yavaşlamıştır. Toprak, artık üst limitlerine yaklaştığının sinyallerini vermeye başlamış olup, bunun sonucu olarak mevcut ürün kaybını minimuma indirme fikri hızla gelişmiştir. Ürün kaybını en aza indirmedeki anahtar ise uygun bir zararlı yönetimi olarak görülmüştür.

1960'lardan bu yana pestisit kullanımı 15-20 kat artmasına rağmen; zararlı, hastalık ve yabancı otlardan kaynaklanan verim kaybının hala yüksek oranda olduğu bilinmektedir (Oerce, 2006). Gelişmiş ülkelerdeki \%25-30 verim kaybı oranına karşın, gelişmekte olan ülkelerde bu oranın \%4050 arasında bir değerde olduğu rapor edilmiştir (Thacker, 2002; Parda ve ark., 2013). Bir milyar insandan fazlasını besleme potansiyeli olan bu ürün kaybı, durumun vahametini daha net bir şekilde gözler önüne sermektedir (Birch ve ark., 2011). Dünya, bu sosyal bedelin yanısıra, sadece eklem bacaklılardan kaynaklanan yıllık yaklaşık 500 milyar dolarlık ekonomik bir bedel ödemektedir (Culliney, 2014). İstatistiksel olarak ifade edilmesi mümkün olmayan bir bedel daha bulunmaktadır; o da ekolojik bedeldir.

Entegre zararlı yönetimi (EZY), temelde bu üç probleme çözüm geliştirmek amacı ile 1960’lı yıllarda geliştirilmiş bir mücadele stratejisidir. Bu derlemede, EZY'nin tarihçesine değinilecek; ülkemizde ve gelişmekte olan ülkelerdeki durumu hakkında bilgi verilecektir. Aynı zamanda, bu ülkelerde EZY'nin neden istenilen düzeye ulaşamadığı tartışılacaktır.

Sadece 1959-2000 yılları arasında bile 67 farklı tanıma sahip olan EZY (Bajwa ve Kogan, 2002), genel anlamıyla zararlıları baskılamak amacıyla mevcut mücadele yöntemlerinin (kültürel, mekanik, biyolojik, kimyasal vb.) güvenli, uygun maliyetli ve çevre dostu bir şekilde kombine edilmesi olarak ifade edilmektedir (Sanyal ve ark., 2008). Bajwa ve Kogan (2002), yapmış oldukları çalışma ile bu 67 farklı EZY tanımını, merkeze alınan kavramlara göre analiz etmişlerdir. Analiz sonucunda odaklanılan konular ve yüzdeleri; ekonomi (\%53,8), çevre (\%48.1), zararlı popülasyonları (\%40.4), zararlı mücadelesi (\%38.3), metotlar ve taktikler (\%26.9), ekoloji (\%25), sistem (\%24.2), mücadele yöntemlerinin kombine edilmesi (\%19.2), ekonomik zarar eşiği/ekonomik zarar seviyesi (\%17.3), optimizasyon/maksimizasyon (\%13.5) ve sosyal/sosyolojik (\%9.6) olarak bildirilmiştir. Bu çalışma, EZY'yi ifade etmede çevreden daha çok ekonominin ön plana alındığını, sosyal boyutun ise adeta göz ardı edildiğini ortaya koymaktadır.

T.C. Tarım ve Orman Bakanlığı ise entegre mücadeleyi "Kültür bitkilerinde zararlı türlerin popülasyon dinamikleri ve çevre ile ilişkilerini dikkate alarak, uygun olan bütün mücadele metotlarını ve tekniklerini uyumlu bir şekilde kullanarak, bunların popülasyonlarını ekonomik zarar seviyesi altında tutan bir zararlı yönetimi sistemi" olarak tanımlamaktadır (TOB, 2018).

EZY'nin amacl, zararlıları tamamen yok etmekten ziyade belirli bir popülasyon yoğunluğunun altında tutmaktır. Bu amaç doğrultusunda "Ekonomik Zarar Seviyesi (EZS)" ve "Ekonomik Zarar Eşiği (EZE)" kavramları kullanılmaktadır. Ekonomik zarar seviyesi; üründe ekonomik zarara neden olabilecek en düşük popülasyon yoğunluğu olarak tanımlanmaktadır (Pedigo ve ark., 1986). “Ekonomik zarar eşiği (EZE)" ise zararlı popülasyonun ekonomik zarar seviyesine ulaşmadan önce önlem alınması gereken yoğunluk seviyesine ulaştığı nokta olarak tanımlanmıştır (Stern ve ark., 1959) (Şekil 1).

EZY, çevre dostu yapısını her şeyden önce sürdürülebilir zararlı yönetimine borçludur. Bir zararlının ortamda bulunması durumunda, EZY piramidindeki basamaklar sırasıyla izlenilmelidir (Şekil 2). EZY, belirli bir felsefeye sahip dinamik bir olgudur. Birbirine çok yakın olan iki arazide bile farklı EZY sistemleri uygulanabilmektedir. EZY'nin amacı, zararlı popülasyonunu tamamen yok etmek yerine, popülasyonu ekonomik zarar eşiğinin altında tutmaktır. Ekonomik zarar eşiği, matematiksel modellere dayanan bir eşik değeridir ve EZY sistemlerinde hedef zararlılar bu eşiğin altında tutulmalıdır. Ancak, ülkemiz ve diğer 
gelişmekte olan ülkeler, genellikle gelişmiş ülkelerin EZE değerlerini kabul etmekte ve uygulamaktadır. Bu durum EZY gibi dinamik bir sistemin felsefesiyle ters düşmektedir. Zararlılar için EZE, ülkeden ülkeye, bölgeden bölgeye, bitkiden bitkiye değişmektedir. Bu nedenle, başlangıç olarak en azından ülkemizdeki belirli ana zararlılara karşı farklı coğrafi bölgelerde eşik değeri hesaplama çalışmalarının yapılması gerekmektedir.

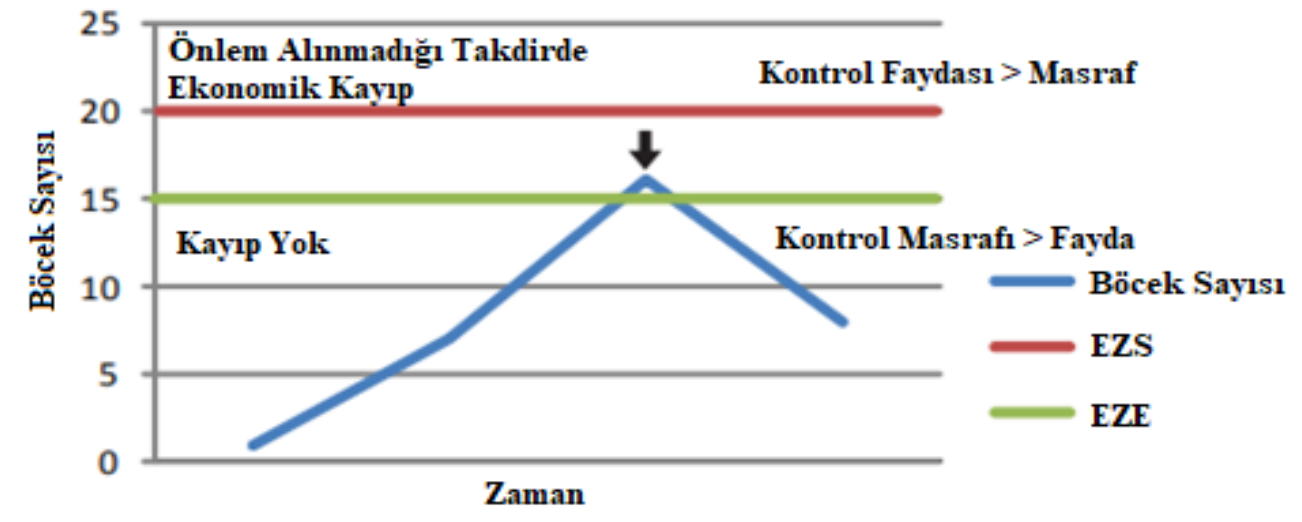

Şekil 1. Ekonomik zarar seviyesi ve ekonomik zarar eşiği grafiği (Alston, 2011)

Figure 1. The graphic of economic threshold and economic injury level (Alston, 2011)

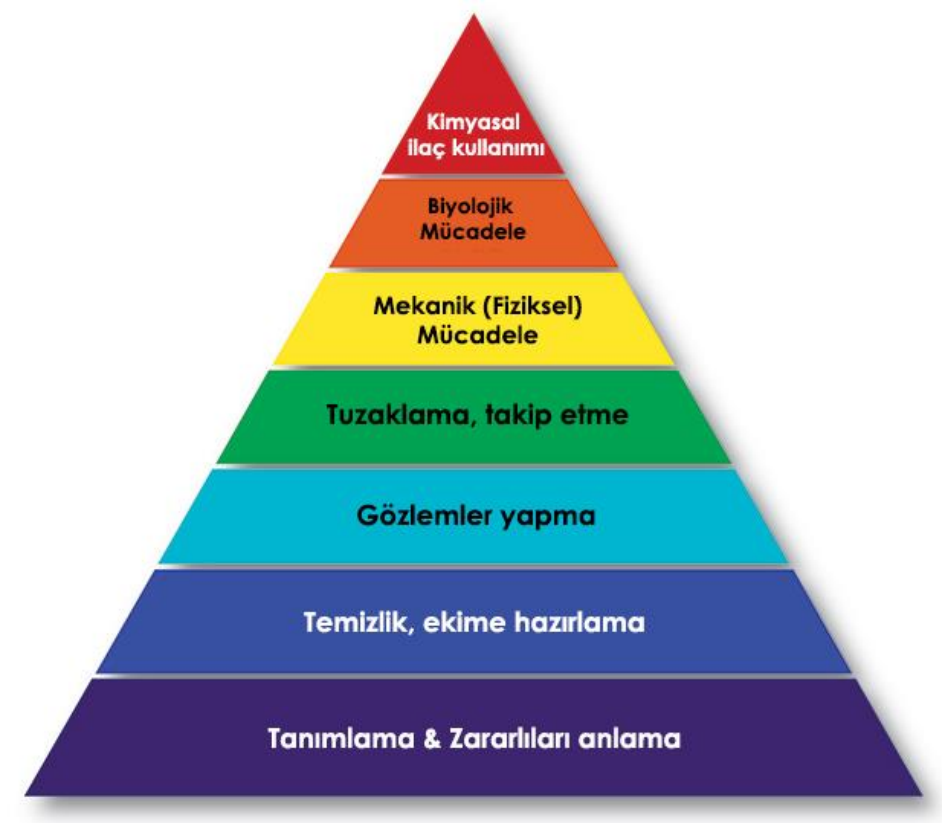

Şekil 2. EZY piramidi (Anonim, 2017)

Figure 2. IPM pyramid (Anonymous, 2017)

EZY'ye benzer felsefede olan, ancak ekolojik tabanlı zararlı yönetimi, biyolojik mücadele tabanlı entegre zararlı yönetimi gibi farklı adlandırmalara sahip zararlı yönetim programları da bulunmaktadır. Bu isim çeşitliliğin sebebi EZY'nin sahip olduğu dinamik yapısı olabilir. Örneğin; ekolojik tabanlı zararlı yönetiminin bazı temel parametreleri Şekil 3'de verilmektedir.
Ülkemizde 2017 yılında Manisa ili bağ alanlarında üretici koşullarında yapılan Biyolojik Mücadele Temelli Entegre Zararlı Yönetimi konulu bir çalışmada, üreticilerin uyguladığı rutin mücadele önlemlerinin yanında, önemli biyolojik mücadele etmenleri olan Trichogramma evanescens ve Bracon hebetor'un yerel kaynaklarla üretilip ana zararlı konumundaki bağ 
salkım güvesine karşı salımları yapılmıştır (Özkan ve ark., 2018). Hastalık ve zararlılara karşı yürütülen bu çalışmanın sonucunda; alternatif mücadele yöntemlerinin doğru kullanımı ve ekonomik zarar eşiğine uyulan ilaçlamalar sonrasında, yöre bağlarında sezonda uygulanan toplam 15 pestisit uygulamasının 7 uygulamaya düşürüldüğü bildirilmiştir (Özkan ve ark., 2018). Bu bağlamda, ülkemizde ve gelişmekte olan diğer ülkelerde ekonomik ve ekolojik olarak ihtiyaç duyulan benzer çalışmaların arttırılması hedeflenmelidir.



Zararlının doğal düşmanlarının yetiştirilmesi ve salımı

'Pull-push' stratejisi = Tuzak bitki ile zararlıyı çekme (pull), Repellent bitki ile zararlıyı uzaklaştırma (push)

\section{Rotasyon}

Bitki Çeşitliliği

Ara Ekim

Örtü Bitkisi

Dayanıklı Çeşit

Toprak işleme yapılmaması

Organik yönetim

Toprağın besin yönetimi

Şekil 3. Ekolojik tabanlı zararlı yönetiminin teknoloji ve pratikleri (Zhao ve ark. 2016)

Figure 3. The technologies and practices of ecologically based pest management (Zhao et al., 2016)

Pratik anlamda EZY'ye karşı en çok kabul edilen bakış ve tanım, pestisit kullanımını azaltmayı hedefleyen "pestisit yönetimi" tanımıdır (Morse ve Buhler, 1997).

Barfield ve Swisher (1994), EZY içerisinde iki farklı düşünce tarzı tanımlamışlardır;

1) EZY'yi aslında pestisit kullanımına daha sorumlu bir yaklaşım olarak görenler (pestisit yönetimi, taktiksel EZY),

2) Belirli girdiler kullanılmadan önce agroekosistemi tamamıyla anlamanın önemini vurgulayanlar (stratejik EZY, gerçek EZY) olarak bilinmektedir.

Stratejik EZY'nin gerçek ve olması gereken EZY türü olduğu, ancak bunun küçük bir kısım tarafından uygulandığını bildirmektedirler (Morse ve Buhler, 1997). Pestisitlerin, stratejik EZY'nin bir parçası olup olmadığı bir tartışma konusudur. Fakat en temel fark olarak; stratejik EZY'de pestisitlerin kullanımı görece basit ve esnek olmayan "zarar eşiği" kavramına göre değil, çok geniş ekolojik bilgiye dayanmasıdır (Morse ve Buhler, 1997). Taktiksel EZY sistemleri ise bazı üretim sistemlerinde (özellikle pamuk gibi yüksek değerli bitkilerde) geniş alanlarda kullanılmaktadır (Zalucki, 2015).

\section{Entegre Zararlı Yönetiminin Tarihçesi}

Bitki koruma uzmanları; pestisitlerin henüz günümüzdeki gibi yaygın olarak kullanılmadığı 20. yüzyılın başlarında çoklu mücadele stratejileri üretmek için, zararlı biyolojisinden yararlanarak mücadele olanakları geliştirmiş ve kültürel önlemleri kullanmışlardır. Bu uzmanlar, modern EZY'nin öncüleri olarak kabul edilmektedirler (Kogan, 1998).

Kogan (1998) tarafından bildirildiği üzere, 
entegre mücadelenin tohumlarını Hoskins ve ark. (1939) şu sözlerle atmıştır: "Biyolojik ve kimyasal mücadele aynı bir kılıcın iki keskin yüzü gibi birbirine destek sağlayacak şekilde düşünülmelidir... Doğanın kendi dengesi, başarılı bir tarımsal mücadelenin en önemli kısmını oluşturmaktadır... Insektisitler, zararlıların doğal mücadelesinin çok az mümkün olduğu durumlarda müdahale etmek için kullanılmalıdır..."

Daha sonraki yıllarda ise Stern ve ark. (1959), entegre mücadele kavramını "biyolojik ve kimyasal mücadeleyi kombine ve entegre eden uygulamalı zararlı mücadelesi" olarak tanımlamıştır. Elbette bu tanım "EZY" teriminin ilk kullanıldığı makalelerden bir tanesi olması yönüyle çok önemli olsa da, daha önce de bahsedildiği gibi, yeni zararlı mücadele tekniklerinin geliştirilmesiyle birlikte zaman içerisinde değişmiştir. Entegre zararlı yönetimi konsepti ilk olarak böceklerin salgın yapması (doğal düşmanların ölümü ve direnç oluşumu gibi sebeplerden ötürü) nedeniyle entomologlar tarafından geliştirilse de, günümüzde hastalık ve yabancı ot dahil bütün zararlı türlerinde kullanılan geniş bir kavram haline gelmiştir. İlk entegre mücadele çalışmaları; yonca tırtılı (Colias eurytheme Boisduval) ve noktalı yonca yaprakbitine [Therioaphis maculata (Buckton)] karşı yapılmıştır (Ehler, 2006).



Şekil 4. EZY ile ilgili yayınlanan makalelerin yıllara göre dağılımı (Young, 2017) Figure 4. Distribution of papers related to IPM by years (Young, 2017)

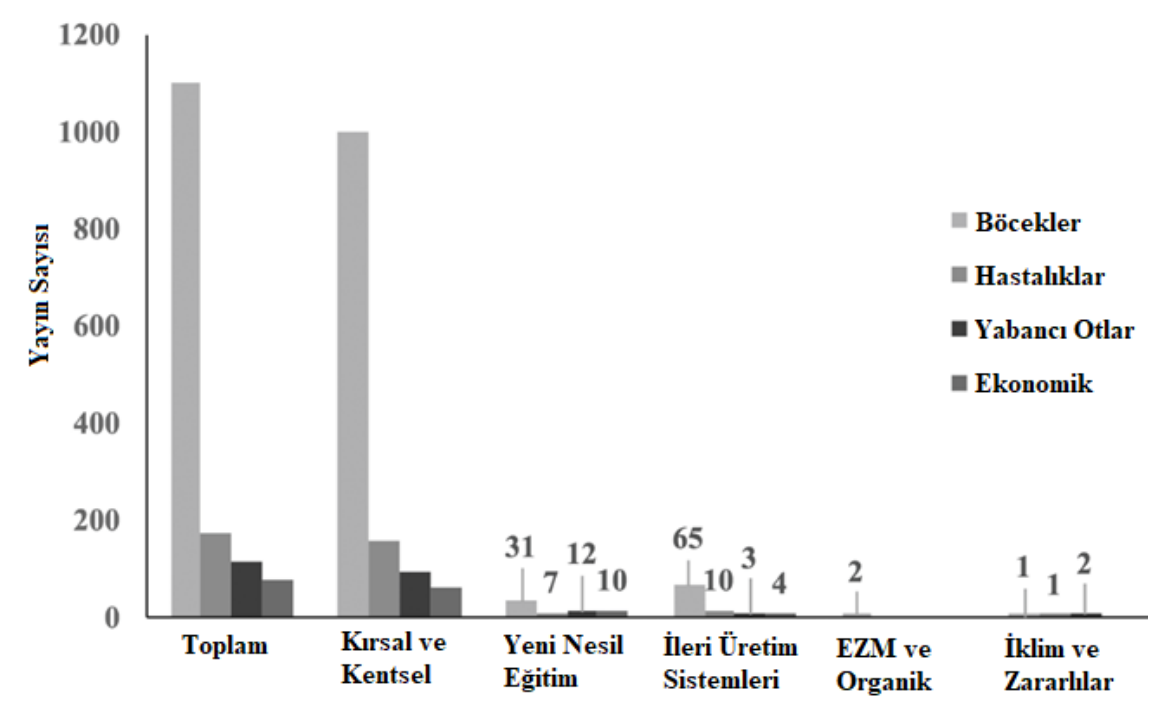

Şekil 5. EZY uygulamalarının kategorileri (Young, 2017)

Figure 5. Categories of IPM applications (Young, 2017)

Özellikle Rachel Carson tarafından 1962 yılında kaleme alınan "Sessiz Bahar" isimli kitap, pestisitlerin insanlara, çevreye ve faydalı organizmalara olan yan etkilerini gözler önüne 
sermiş, entegre mücadelenin benimsenmesi ve yaygınlaşmasında büyük rol oynamıştır.

Sonrasında EZY ile ilgili uygulamalar, çalışmalar ve yayınlar hızlı bir artış göstermiştir (Şekil 4). Bu araştırmaların çok önemli bir kısmını ise böcekler hakkındaki kırsal ve kentsel alanlarda yapılan çalışmalar oluşturmaktadır (Şekil 5).

Ülkemizde ise 1995 yılında, buğday, mısır, pamuk, patates, nohut, mercimek, örtü altı sebzeleri, elma, turunçgiller, şeftali, kiraz, kayısı, zeytin, fındık, antepfıstığı ve bağ gibi toplam 16 kültür bitkisinde, çeşitli hastalık, zararlı ve yabancı otların mücadelesi için, entegre mücadele uygulama ve eğitimler başlamıştır (Delen ve ark., 2010). Başlatılan bu çalışmalara ait bazı bilgiler (süre, alan, eğitilen üretici ve teknik eleman sayıları vb.) Karaturhan ve ark. (2005) tarafından bildirilmiştir. Projeler sonucunda ilaçlama sayılarındaki değişim ise Çizelge 1.'de görülmektedir (Kutlar, 2008).

Çizelge 1. Türkiye'de EZY projeleri sonucunda pestisit uygulama sayılarındaki değişim (Kutlar, 2008)

Table 1. Changes in the number of pesticide applications as a result of IPM projects in Turkey (Kutlar, 2008)

\begin{tabular}{|c|c|c|}
\hline & $\begin{array}{c}\text { EZY alanlarında } \\
\text { uygulanan pestisit sayısı } \\
\text { The number of pesticide applications in IPM areas }\end{array}$ & $\begin{array}{c}\text { Konvansiyonel alanlardaki } \\
\text { uygulanan pestisit sayısı } \\
\text { The number of pesticide applications in } \\
\text { conventional areas }\end{array}$ \\
\hline $\begin{array}{l}\text { Misır } \\
\text { Maize }\end{array}$ & 1-2 (Parazitoit uygulandığında "0") & $3-4$ \\
\hline $\begin{array}{l}\text { Elma } \\
\text { Apple }\end{array}$ & $4-9$ & $11-22$ \\
\hline $\begin{array}{c}\text { Turunçgil } \\
\text { Citrus } \\
\end{array}$ & $1-3$ & $2-6$ \\
\hline $\begin{array}{c}\text { Bağ } \\
\text { Vineyard }\end{array}$ & $3-6$ & $10-13$ \\
\hline $\begin{array}{l}\text { Kiraz } \\
\text { Cherry }\end{array}$ & $1-2$ & $3-4$ \\
\hline \multicolumn{3}{|l|}{$\begin{array}{c}\text { Örtüaltı } \\
\text { Greenhouses }\end{array}$} \\
\hline Hatay & 5 & 10 \\
\hline Antalya & 19 & 49 \\
\hline Finike & 10 & 16 \\
\hline Ege Bölgesi & $1-3$ & $25-30$ \\
\hline
\end{tabular}

Gelişmekte Olan Ülkelerde Entegre Zararlı Yönetimi

Günümüzde yıllık kullanılan aktif madde miktarı yaklaşık 3.5 milyar kg olup, toplam küresel pestisit pazarı ise 45 milyar dolardır (Pretty ve Bharucha, 2015). Pretty ve Bharucha (2015)'nın US EPA raporuna (2007) atfederek belirttiği üzere, dünyada toplam pestisit kullanımın \%63'ünü tarım sektörü oluştururken, \%16'sını devlet aktiviteleri (anayollardaki yabancı otların mücadelesi ve ormanlık alanlarda vb.) ve $\% 22$ 'sini ev ve bahçelerdeki kullanım oluşturmaktadır.

Gelişmekte olan ülkelerin büyük çoğunluğunun ana geçim kaynağının tarım olduğu ve tüm dünyadaki yoğun pestisit kullanımı göz önüne alındığında, bu ülkelerde EZY sisteminin yaygın hale getirilmesinin önemi daha net bir şekilde ortaya çıkmaktadır.

Büyük ihtiyaca rağmen, gelişmekte olan ülkelerde EZY sisteminin istenilen düzeyde kabul görmediği görülmektedir. Bunun nedenlerini ise Parsa ve ark. (2013), gelişmekte olan ülkelerdeki EZY uzmanı ve uygulayıcıları ile yaptıkları araştırmada bildirmişlerdir (Çizelge 2).

Dasgupta ve ark. (2007), Bangladeş çeltik üretim alanlarında EZY uygulanan ile konvansiyonel mücadele yapılan üretim arasında verim açısından önemli bir farklılık olmadığını, ancak EZY uygulanan alanlarda daha az pestisit kullanıldığını ve bu sayede EZY uygulanan alanların daha karlı olduğunu bildirmişlerdir. 
Çizelge 2. Gelişmekte olan ülkelerde EZY sisteminin istenilen yaygınlığa ulaşmasının önündeki engeller (Parsa ve ark., 2013) Table 2. Obstacles to integrated pest management system adoption in developing countries

\begin{tabular}{|l|c|}
\hline $\begin{array}{l}\text { Nedenler } \\
\text { Reasons }\end{array}$ & $\begin{array}{c}\text { Sıklık } \\
\text { Frequency (\%) }\end{array}$ \\
\hline 1) Çiftçiye yetersiz teknik destek ve eğitim sağlanması & 53 \\
\hline 2) Uygun devlet politikaları ve desteği eksikliği & 39 \\
\hline 3) Çiftçilerin düşük eğitim ve okuma yazma seviyesine sahip olması & 22 \\
\hline 4) EZY'nin konvansiyel mücadele ve pestisitlerle karşılaştırılığında uygulanmasının çok zor olması & 18 \\
\hline 5) Pestisit endüstrisinin güçlü etkisi & 16 \\
\hline 6) EZY desteklenmesinde eksiklik (özellikle uzun-dönem desteklemeleri) & 16 \\
\hline 7) EZY girdilerine ulaşımdaki zorluk (dayanıklı çeşit ya da biyopestisitler gibi) olarak değerlendirilmiştir. & 15 \\
\hline
\end{tabular}

Kibira ve ark. (2015), Kenya mango üretim alanlarında meyve sineğine karşı EZY uygulanan alanlarda; insektisit kullanımının \%46,3 azaldığını, EZY uygulamayanlara göre \%22.4 oranında daha fazla kar elde edildiğini bildirmişlerdir. Ayrıca, meyve sineği nedeniyle mango üretimi yapmak istemeyen üreticilerde ise \%54.5'lik bir azalış olduğu bildirmişlerdir.

Schreinemachers ve ark. (2015), Güneydoğu Asya'da güvenli ve sürdürülebilir bitki koruma hakkında yaptıkları çalışmada pestisit riskini azaltmada 3 ana engel bildirmişlerdir. Bunlar; a) pestisit ticaretindeki hızlı büyüme (toplam miktar, pestisit sayısı, satış noktaları ve bunlara karşı bulunan zayıf yasalar ve yaptırım kapasitesi), b) çiftçilerin pestisitlere karşı olan yüksek memnuniyet seviyesi ve risk bilincinin düşük olması, EZY hakkında teknik bilgi eksikliği ve biyolojik mücadele ajanlarının bulunmayışı gibi nedenlerle birleşimi, c) akılcı karar vermeyi sağlayan, pestisit riski için düzenli gözlemin olmaması gibi nedenler olarak tanımlanmıştır.

Pretty ve Bharucha (2015), 1990-2014 yılları arasında 24 Asya ve Afrika ülkesinde yapılan 85 IPM projesini incelemişlerdir. Proje çıktılarına bakıldığında; ortalama verimin \%41 oranında arttı̆̆ı, pestisit kullanımının ise $\% 30$ oranında azaldığı görülmüştür.

TSC (Targeted staggered control $=$ Hedeflenmiş kademeli kontrol), Batı ve Orta Afrika'da pamuk üretim alanlarında pestisit kullanımını azaltmak ve geliri arttırmak için ortaya çıkarılan bir EZY teknolojisidir. Kuzey Benin'de yapılan bir çalışmada, çiftçilerin \%87.3'ünün TSC servislerine para ödemeye istekli olduğu bildirilmiştir (Kpade ve ark., 2017).

\section{Türkiye'de Entegre Zararı Yönetimi Çalışmaları}

Türkiye; \%35.6'sı ekilebilir alan, \%28'i çayırmera, \%30.2'si orman ve ağaçlık alan olmak üzere toplam 77.8 milyon hektar alana sahip bir ülkedir. Ülkemiz; 8.5 milyon hektar sulanabilir, ekonomik olarak ekilebilir alanı ile tarımsal üretimde önemli potansiyele sahip bir ülkedir (Akkaya ve ark., 2006).

Son 20 yıllık süreçte (1990-2011) Türkiye'deki pestisit kullanım durumuna bakacak olursak; pestisit kullanımında 1.4 katlık bir artış olduğu bildirilmiştir (Pretty ve Bharucha, 2015).

Demirci ve ark., (2005) tarafından, Ankara ili Ayaş ve Nallıhan ilçelerinde domates üreticilerinin kullandıkları tarım ilaçlarını seçerken \%44'ünün tarım ilçe müdürlüklerine danıştıkları, \%22'sinin ilaç bayilerinin tavsiyelerine uydukları bildirilmiştir.

Karaturhan ve ark. (2005), Ege bölgesi seralarında EZY uygulanan alanlarda ilaçlamaların \%30-100 oranında azaldığını bildirmişlerdir. Özellikle domateste, zararlılara karşı hemen hemen hiç ilaçlama yapılmadığını bildirmişlerdir.

Öğüt ve Küçüköner (2007) yaptıkları çalışmada Isparta ilinde 100'den fazla üretici ile ilaç seçimini neye göre yaptıklarını araştırmışlardır. Buna göre, üreticilerin \%36.9'u kendi tecrübelerine, \%28.8'i ilaç bayi tavsiyeleri, \%16.2'si diğer üretici tavsiyeleri, \%11.7'si tarım il/ilçe müdürlüklerinden, \%6.3'ü görsel ve basılı kaynaklardan faydalandıklarını bildirmiştir.

Kutlar ve Ceylan (2008), Antalya ilinde başlangıc 1994 yılına dayanan "Entegre Mücadele Araştırma, Uygulama ve Eğitim" projesine katılan ve katılmayan üreticilerin tarımsal mücadelede 
uyguladıkları yöntemler bakımından önemli bir fark olmadığını; dahası, projeye katılan üreticiler arasında entegre mücadelenin hala tanınmadığını bildirmişlerdir.

Bayraktar ve Saner (2010), Muğla ilinde yürüttükleri çalışmada; entegre mücadele uygulanan seralarda kimyasal mücadelenin zamanında, uygun dozda ve uygun şekilde kullanıldığı bildirilmiştir. Bunun yanısıra, bu seralarda ilaç, gübre, tohum/fide kullanımının azaldığı, genel anlamda masraf düzeyinin düştüğü bildirilmiştir.

Ceylan ve ark. (2010), Antalya ilinde EZY uygulamalarına uyum sağlamadaki faktörleri belirlemişlerdir. Buna göre; arazi büyüklüğü, tarım dışı gelir, bilgi kaynağı, yaş ve eğitimin EZY uygulamalarına çok önemli etkisi olduğu tespit edilmiştir. Ayrıca, eğitim düzeylerinin sadece 1 yıl artmasıyla, EZY uygulamalarının 6.75 kat arttığı bildirilmiştir.

Turgut ve ark. (2011), Türkiye'de sofralık üzümlerde pestisit kalıntısına yönelik yaptıkları çalışmada, sadece konvansiyonel tarım uygulamalarının yapıldığı alanlarda pestisit kalıntısının tespit edildiğini, EZY uygulamalarının olduğu alanlarda ise kalıntı olmadığını bildirmişlerdir.

Gül ve ark. (2016), kiraz üretim alanlarında yaptıkları çalışmada, üreticilerde entegre zararlı yönetimi bilincinin düşük olduğunu bildirmişlerdir. Kiraz ithalatı yapılmaya başlandıktan sonra EZY'nin daha çok uygulamaya geçtiği belirtilirken; üreticilerin \%37.3'ünün yüksek düzeyde $E Z Y$ uyguladığı, \%22.5'inin ise düşük seviyede olduğu bildirilmiştir.

Gül ve ark. (2017a), yaptıkları çalışmada Tarım ve Orman Bakanlığı teknik personellerinin entegre zararlı mücadelesi hakkındaki bilgilerinin istenilen seviyede olmadığını bildirmiştir.

Gül ve ark. (2017b), elma bahçelerinde EZY uygulama oranının \%19.5 olduğunu ve eğitim seviyesi arttıkça EZY adaptasyonunun arttığını bildirmiştir. Bu çalışmada; $1 \mathrm{~kg}$ elma üretmek için gerekli olan maliyetin EZY uygulanmayan alanlarda daha fazla olduğu bildirilse de, toplam net gelirin ise EZY uygulaması yapılan alanlarda daha düşük olduğu bildirilmiştir. Bunun nedeni olarak ise bu alanlarda verim ve birim satış fiyatının daha yüksek olması olarak bildirilmiştir.

\section{Sonuç}

Tarıma sadece zararlı yönetimi çerçevesinden değil, bir bütün olarak bakılması bir zorunluluk haline gelmiştir. Bu bütünlüğün bozulmaması için, tarımsal üretim sistemlerinin sürdürülebilir olması gerekmektedir. Sürdürülebilir bir sistem ise: yüksek verimli bitki çeşitlerinden yararlanılması; dış girdilerin gereksiz kullanımından kaçınılması; biyolojik azot fiksasyonu, besin döngüsü, allelopati, predatör ve parazitizm gibi tarımsal süreçlerden faydalanılması; çevreye ve insan sağlığına olumsuz etkileri olan teknolojilerin kullanımının minimuma indirilmesi; sistem yönetiminin sera gazı emisyonu, temiz su, karbon tutma, biyoçeşitlilik, zararlılar, patojen ve yabancı otların dağılımı üzerindeki etkilerin minimize edilmesi; lokal ve küresel problemlerin (su, zararlı ve toprak yönetimi gibi) çözümü için sermayenin etkili kullanımı gibi bazı parametrelere uyulmasıyla mümkün olmaktadır (Pretty ve Bharucha, 2015).

Sürdürülebilir tarımda etkili bir zararlı yönetimi ise ancak EZY ile mümkün olmaktadır. Fakat, bütün olumlu özelliklerinin yanında EZY ile ilgili bazı olumsuz düşünceler ve karşıt görüşler de bulunmaktadır. Fenemore ve Norton (1985), ekonomik olarak yüksek değere sahip meyvelerde, EZY yerine fazla pestisit girdili üretimin daha fazla tercih edildiğini bildirmiştir. Bunun nedenleri olarak; görsel bozuklukların tüketici tarafından kabul edilmemesi ve EZY'de mücadeleye başlamak için gerekli olan sürekli gözlemlerin yüksek maliyeti gibi nedenler bildirilmiştir. Zalucki ve ark. (2009) ise, EZY sistemlerinin özellikle küçük ölçekli üretim yapılan yerlere uygun olmadığını, bu tür üreticilerin çoğu zaman ekonomik riski en düşük seviyeye indiren uygun maliyetli yöntemleri tercih etme eğiliminde olduğunu bildirmiştir.

Ayrıca, EZY uygulamalarının; "stabil" mi yoksa "sürdürülebilir" mi olduğu, herhangi bir kriz 
anında sekteye mi uğrayacağı merak uyandırmaktadır. EZY sistemlerinin bu krizleri atlatmak için sadece büyük kimya firmaları tarafından yeni insektisitlerin piyasaya çıkarılmasını veya transgenik bitkiler tarafından üretilen yeni bir toksini mi bekleyeceği konusunda da eleştiriler bulunmaktadır (Zalucki ve ark., 2014).

EZY programlarında bazı istisnalar haricinde (parazit salımı gibi), üreticiler büyük rol oynamaktadır. Bu nedenle, gelişmekte olan ülkelerde $E Z Y$ 'nin yaygınlaşmasındaki en önemli adımlardan bir tanesi üreticilerin bilgilendirilmesidir.

EZY sistemlerinin daha etkin kullanılmasını engelleyen bir faktör de yetersiz ülke içi ve ülkeler arası haberleşmedir (Lamichhane ve ark., 2016). $\mathrm{Bu}$ nedenle, benzer ürün deseni ve zararlılara sahip ülkelerle ortak bir zararlı mücadele ağı kurulmalıdır. Gelişmiş ülkelerin uzun yıllardır kullanmakta olduğu haberleşme ağlarını, gelişmekte olan ülkelerin de kendi sınırları içerisinde benzer şekilde kurarak, EZY'nin daha doğru kullanımını ve yaygınlaşmasını sağlayacakları düşünülmektedir.

Ülkemizde, insektisit ruhsat sürecinde faydalı böcek ve akarlara karşı etki çalışmaları sadece turunçgillerde zorunlu haldedir. Bu uygulama örnek teşkil etmeli ve daha çok kültür bitkisinde gerçekleştirilmelidir. Sürdürülebilir bir tarım ve entegre zararlı yönetimi için, bu programların daha çok kültürel ve biyolojik mücadeleye dayandırılması gerekmektedir.

EZY sistemleri sabit olmadığından, başka bölgelerde tasarlanmış bir sistemi alıp aynen uygulamaya çalışmak büyük bir hata olacaktır. Çünkü her ülkenin doğal olarak yerleşmiş farklı faydalı/zararlı organizmaları bulunmaktadır ve başka bir ülkeden doğrudan alınıp uygulanmaya çalışacak olan bir sistem bu organizmaları göz ardı edebilir. Bu durum EZY felsefesine uymamaktadır. Bunların önüne geçmek için mutlaka ülke içi zararlı yönetim sistemlerinin araştırıp geliştirilmesi gerekmektedir.

Ülkemiz, biyolojik çeşitlilik açısından çok zengin bir coğrafyada yer almaktadır. Ancak ne yazık ki, ülkemizde çok az ve yetersiz sayıda biyolojik mücadele etmeninin üretimi yapılmaktadır. Biyolojik mücadele etmenlerinin yerli üretiminin artması, hem maliyeti düşürüp biyolojik mücadelenin yaygınlaşmasını hem de binlerce yıldır bu coğrafyaya uyum sağlamış yerli popülasyonların kullanılması ile biyolojik mücadelenin daha etkin yapılmasını sağlayacaktır.

EZY'nin iyi bir şekilde uygulanması ile son yıllarda uluslararası ticarette büyük sorunlar yaratan pestisit kalıntı probleminin de önüne geçilebilir. Aynı sistem, zararlılardan oluşan ürün kaybının daha az olması ile daha fazla ürün elde etmeyi sağlayacaktır. EZY'nin bu iki olumlu özelliği, ihracatı ve dolayısıyla ülkemiz gelirlerini arttırma potansiyeline sahiptir.

Kalıntı problemi ile doğru orantılı olarak, yine son yıllarda sıkça üzerinde durulan "Gıda Güvenliği" için iyi planlanmış EZY sistemleri çözüm vaat etmektedir. Ülkemizde "Gıda güvenilirliği" seviyelerini olabildiğince üst seviyelere getirmek, gerek iç gerek dış piyasada hareketliliği beraberinde getirecektir.

Sonuç olarak, ülkemizde ve diğer gelişmekte olan ülkelerde, sürdürülebilir ve çevre dostu zararlı mücadele sistemlerine acil ihtiyaç bulunmaktadır. Çevreyi, geri dönüşü olmayan kirliliklere maruz bırakmadan, onunla uyum içerisinde yaşamak öncelikli hedefler arasında olmalıdır. Bunu sağlamak için, tarımsal alanlarda EZY sistemlerinin yaygınlaşması gerekmektedir ve bu da ancak yeterli bir bilgi birikimi ve eğitim ile gerçekleşebilecektir.

\section{Kaynaklar}

Akkaya, F., Yalçın, R. \& Özkan, B. (2006). Good agricultural practices and its implementation in Turkey. Acta Horticulturae, 699, 47-52.

Alston, D.G. (2011). https://digitalcommons.usu.edu/ cgi/viewcontent.cgi $?$ article $=2754$ \& context=extensio n_curall. Access date:15.01.2018

Anonim. (2017). http://dumanlarziraat.com/2017/08/10/ entegre-mucadele/?lang=ua. Erişim tarihi: 10.01. 2018

Bajwa, W.I. \& Kogan, M. (2002). Compendium of IPM definitions (CID) - What is ipm and how is it defined in the worldwide literature? IPPC Publication No. 998, Integrated Plant Protection Center (IPPC), Oregon State University, Corvallis, OR 97331, USA.

Barfield, C.S. \& Swisher, M.E. (1994). Integrated pest 
management: ready for export? Historical context and internationalization of IPM. Food Reviews International, 10(2), 215-267.

Bayraktar, Ö.V. \& Saner, G. (2010). Ege bölgesinde entegre mücadele programı uygulanan örtüaltı domates yetiştiriciliğinin teknik ve ekonomik özelliklerinin incelenmesi: Muğla ili örnek olayı. Türkiye IX. Tarım Ekonomisi Kongresi, 22-24 Eylül, pp. 143-150, Şanlıurfa, Türkiye.

Birch, A.N.E., Begg, G.S. \& Squire, G.R. (2011). How agroecological research helps to address food security issues under new IPM and pesticide reduction policies for global crop production systems. Journal of Experimental Biology, 62(10), 3251-3261.

Carson, R. (1962). Silent spring. Riverside press, Boston, 368 $\mathrm{pp}$.

Ceylan, C., Köksal, O. \& Kutlar, I. (2010). Determination of effectice factors on adoption of integrated pest management practices. Journal of Environmental Protection and Ecology, 11 (2), 709-717.

Culliney. T. (2014). Crop Losses to Arthropods “ Alınmıştır: Integrated Pest Management. (Ed) Pimentel, D., Peshin, R., Springer, Dordrecht, Holland, 201-225pp.

Dasgupta, S., Meisner, C. \& Wheeler, D. ( 2007). Is environmentally friendly agriculture less profitable for farmers? Evidence on integrated pest management in Bangladesh. Review of Agricultural Economics, 29(1), 103-118.

Delen, N., Kınay, P., Yıldız, F., Yıldız, M., Altınok, H.H. \& Uçkun, Z. (2010). Türkiye tarımında kimyasal savaşımın durumu ve entegre savaşım olanakları. VII. Türkiye Ziraat Mühendisliği Teknik Kongresi, 11-15 Ocak, s. 609-625, Ankara, Türkiye.

Demirci, F., Erdoğan, C. \& Tatlıdil, F.F. (2005). Ankara ili ayaş ve nallıhan ilçelerinde domates üretim alanlarında zirai mücadele uygulamaları. Tarım Bilimleri Dergisi, 11(4), 422-427.

Ehler, L.E. (2006). Integrated Pest Management (IPM): Definition, historical development and implementation, and the other IPM. Pest Management Science, 62(9), 787-789.FAO, 2017. http://www.fao.org/state-of-food-securitynutrition/en/. Access Date: 24.01.2018

Fenemore, P.G. \& Norton, G.A. (1985). Problems of implementing improvements in pest control: a case study of apples in the UK. Crop protection, 4(1), 5170.

TOB, 2018. https://www.tarimorman.gov.tr/ Erişim tarihi: 05.09.2018.

Gül, M., Akpınar, M.G., Demircan, V., Yilmaz, H., Bal, T., Arıcı, Ş.E., Polat, M., Örmeci Kart, M.Ç. \& Acar, M. (2016). Economic analysis of integrated pest management in cherry cultivation. Scientific Papers Series Management, Economic Engineering in Agriculture and Rural Development, 16(2), 165-178.

Gül, M., Akpınar, M.G., Demircan, V., Yilmaz, H., Bal, T., Arıcı, Ş.E., Polat, M., Şan, B., Eraslan, F., Örmeci Kart, M.Ç., Gürbüz, D. \& Yılmaz, G.Ş. (2017a). Technical staff's knowledge level about integrated pest management and their features. Scientific Papers Series-Management, Economic Engineering in Agriculture and Rural Development, 17(2), 157-163.
Gül, M., Akpınar, M.G., Demircan, V., Yilmaz, H., Bal, T., Arıcı, Ş.E., Polat, M., Şan, B., Eraslan, F., Örmeci Kart, M.Ç., Gürbüz, D. \& Yılmaz, G.Ş. (2017b). Economic analysis of integrated pest management adoption in apple cultivation: a Turkish Case Study. ErwerbsObstbau, 59(2), 147-154.

Hoskins, W.M., Borden, A.D. \& Michelbacher, A.E. 1939. Recommendations for a more discriminating use of insecticides. Proceeding. 6th Pac. Sci. Congr. 5, 11923.

Karaturhan, B., Boyacı, M. \& Yaşarakıncı, N. (2005). Ege bölgesinde entegre mücadelenin yayımında karşılaşılan sorunlar: örtü altı sebze yetiştiriciliği örneği. Ege Üniversitesi Ziraat Fakültesi Dergisi, 42(2), 155-166.

Kibira, M., Affognon, H., Njehia, B., Muriithi, B., Mohamed, S. \& Ekesi, S. (2015). Economic evaluation of integrated management of fruit fly in mango production in Embu County, Kenya. African Journal of Agricultural and Resource Economics, 10(4), 343353.

Kogan, M. (1998). Integrated pest management: historical perspectives and contemporary developments. Annual Review of Entomology, 43(1), 243-270.

Kpadé, C.P., Mensah, E.R., Fok, M. \& Ndjeunga, J. (2017). Cotton farmers' willingness to pay for pest management services in northern Benin. Agricultural Economics, 48(1), 105-114.

Kutlar, i. (2008). Antalya ili merkez ilçesinde entegre mücadele yönteminin yayılması ve benimsenmesi. Doktora Tezi, Ankara Üniversitesi, Fen Bilimleri Enstitüsü, Tarım Ekonomisi Anabilim Dalı, Ankara, $133 \mathrm{~s}$.

Kutlar, ì. \& Ceylan, i.C. (2008). Antalya ili merkez ilçesinde entegre mücadele yönteminin yayılması ve benimsenmesi. Bahçe, 37(1), 25-33.

Morse, S. \& Buhler, W. (1997). Integrated pest management: ideals and realities in developing countries. Lynne Reinner, Boulder, London, $171 \mathrm{pp}$.

Oerke, E.C. (2006). Crop losses to pests. Journal of Agricultural Science, 144(1) , 31-43.

Öğüt, S. \& Küçüköner, E. (2007). Isparta da Kullanılan Tarım Ilaçlarına Karşı Üreticilerin Tutum ve Davranışları. Tarım Ilaçları Kongre ve Sergisi. 25-26 Ekim, Ankara, 378-385.

Özkan, C., Atay, I.., Tatlı, Ş., Mert, M.A., Kaya, I., Kayhan, M., Aksu, K., Kılıç, A., Karabat, S., Savaş, N.G., Albaz, E., Aşık, M., Boz, S., Aslan, M.A., Altun, A., Cinbaz, T. \& Ok, Y. 2018. Bağda Akıllı Böcek, Akıllı Çiftçi. Çanakkale Onsekiz Mart Üniversitesi 1. Proje Pazarı, Çanakkale.

Parsa, S., Morse, S., Bonifacio, A., Chancellor, T.C.B., Condori, B., Crespo-Perez, V., Hobbs, S.L.A., Kroschel, J., Ba, M.N., Rebaudo, F., Sherwood, S.G., Vanek, S.J., Faye, E., Herrera, M.A. \& Dangles, O. (2014). Obstacles to integrated pest management adoption in developing countries. PNAS,111 (10), 3889-3894.

Pedigo, L.P., Hutchins, S.H. \& Higley, L.G. (1986). Economic injury levels in theory and practice. Annual Review of Entomology, 31(1), 341-368.

Pretty, J. \& Bharucha, Z.P. 2015. Integrated pest management for sustainable intensification of 
agriculture in Asia and Africa. Insects, 6(1), 152-182.

Sanyal, D., Bhowmik, P.C., Anderson, R.L. \& Shrestha, A. (2008). Revisiting the perspective and progress of integrated weed management. Weed Science, 56(1), 161-167.

Schreinemachers, P., Afari-Sefa, V., Heng, C.H., Dung, P.T.M., Praneetvatakul, S. \& Srinivasan, R. (2015). Safe and sustainable crop protection in Southeast Asia: status, challenges and policy options. Environmental Science \& Policy, 54, 357366.

Stern, V.M., Smith, R.F., Van den Bosch, R.R. \& Hagen, K. (1959). The integration of chemical and biological control of the spotted alfalfa aphid: the integrated control concept. Hilgardia, 29(2), 81-101.

Thacker, J. (2002). An Introduction to Arthropod Pest Control. Cambridge Univ Press, Cambridge, 380pp.

Turgut, C., Ornek, H. \& Cutright, T.J. (2011). Determination of pesticide residues in Turkey's table grapes: the effect of integrated pest management, organic farming, and conventional farming. Environmental Monitoring and Assessment, 173(1-4), 315-323.

Young, S.L. (2017). A systematic review of the literature reveals trends and gaps in integrated pest management studies conducted in the United States. Pest Management Science, 73(8), 1553-1558.

Zalucki, M.P., Adamson, D. \& Furlong, M.J. (2009). The future of IPM: whither or wither? Austral Entomology, 48(2), 85-96.

Zalucki, M.P., Furlong, M.J., Schellhorn, N.A., Macfadyen, S. \& Davies, A.P. (2015). Assessing the impact of natural enemies in agroecosystems: toward "real" IPM or in quest of the Holy Grail? Insect Science, 22(1), 1-5.

Zhao, Z.H., Reddy, G.V., Hui, C. \& Li, B.L. (2016). Approaches and mechanisms for ecologically based pest management across multiple scales. Agriculture, Ecosystems \& Environment, 230, 199-209. 